\title{
EFEITO DO PROCESSO DE SECAGEM DA POLPA DE ABACATE (Persea americana Mill) SOBRE A QUALIDADE DO ÓLEO BRUTO EXTRAÍDO
}

\author{
J. D. F. da SILVA ${ }^{1}$; H. L. GOUVEIA ${ }^{1}$; L. K. SCHEIK $^{1}$; C. C. da CUNHA ${ }^{1}$; C. D. BORGES ${ }^{1}$; C. R. \\ B. MENDONÇA ${ }^{1}$ \\ ${ }^{1}$ Universidade Federal de Pelotas (UFPEL), Centro de Ciências Químicas Farmacêuticas e de \\ Alimentos (CCQFA) \\ E-mail para contato: caroldellin@hotmail.com; carlaufpel@ hotmail.com
}

\begin{abstract}
RESUMO - O conhecimento da influência de diferentes operações unitárias sobre a qualidade do óleo de abacate é uma ferramenta indispensável para a otimização do seu processo de produção. Objetivou-se investigar o efeito do processo de secagem da polpa de abacate sobre a qualidade do óleo bruto. Os abacates da variedade Breda tiveram a polpa separada, tratada com solução de ácido cítrico e triturada. A polpa foi, então, dividida em três porções e submetida a secagem em estufa sob ventilação a $40{ }^{\circ} \mathrm{C}$, em estufa sob ventilação a $60^{\circ} \mathrm{C}$ e por liofilização. O óleo foi extraído em Soxhlet com éter de petróleo. Avaliaram-se nos óleos os índices de acidez, iodo, peróxidos e refração. Os resultados demonstraram que os parâmetros de qualidade avaliados, em geral, variam segundo o processo de secagem aplicado à polpa. De um modo geral, quanto maior a temperatura do processo de secagem, maiores modificações foram observadas. O óleo obtido da polpa liofilizada apresentou, estatisticamente, menores alterações nos parâmetros estudados, comparado aquele obtido da polpa de abacate seca a $40{ }^{\circ} \mathrm{C}$ ou a 60 ${ }^{\circ} \mathrm{C}$. Os índices de peróxidos e acidez foram os parâmetros que mostram maiores variações. Em relação ao índice de peróxidos, observou-se efeito negativo do aumento da temperatura de secagem, entretanto, no índice de acidez (maior para o óleo da polpa seca a $40^{\circ} \mathrm{C}$ ), observou-se efeito deletério do tempo de secagem, que foi maior no processo de estufa a $40^{\circ} \mathrm{C}$, e pode ter possibilitado a ação de lipases.
\end{abstract}

\section{INTRODUÇÃO}

O abacate é uma fruta tropical considerada excelente fonte de ácidos graxos essenciais e de antioxidantes naturais, como tocoferóis e compostos fenólicos, estando o seu consumo, portanto, associado a benefícios à saúde humana. Entretanto, esses compostos podem sofrer oxidação em função de diversas variáveis ao longo da sua cadeia de produção, inclusive nas etapas de processamento, perdendo, então, suas propriedades fisiológicas. Assim, a influência de diferentes operações unitárias sobre a sua qualidade tem sido, extensivamente, pesquisada por diferentes segmentos industriais (Jacobo-Velázquez; Hernández-Brenes, 2012). 


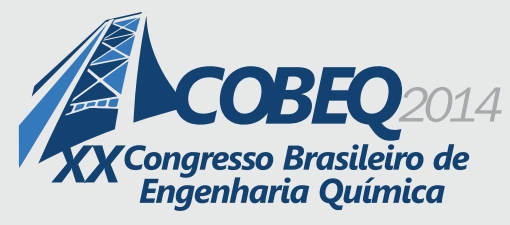

19 a 22 de outubro de 2014
Florianópolis/SC

No processo de extração do óleo de abacate, uma etapa crítica, à ocorrência dessas alterações, pode ser a de secagem da polpa. Essa etapa preliminar tem como função reduzir a sua umidade a níveis que lhe condicione propriedades mecânicas e físico-químicas para a extração de óleo (Santana et al., 2011). Convencionalmente, a secagem de matérias-primas alimentícias se dá por sua exposição a binômios tempo-temperatura, cuja intensidade pode possibilitar a ocorrência de reações de oxidação e degradação de lipídios e compostos fenólicos. Como alternativa a esse problema, tem-se lançado mão de procedimentos de secagem a frio, tal como o processo de liofilização (Fennema, 1993). Esse processo conduziu a produção de óleo de abacate com menores alterações físico-químicas, devido às temperaturas moderadas aplicadas (Santos et al., 2014), entretanto, a liofilização apresenta elevado custo de operação (Fennema, 1993).

Considerando que são escassos os estudos aplicados a avaliar as operações unitárias, ao longo do processamento de abacate, para obtenção de seus derivados, produzir informações desta natureza contribui com a otimização dos processos, aliando a qualidade do produto e a manutenção de suas propriedades nutracêuticas (Santos et al., 2014). Diante do exposto, objetivou-se estudar o efeito comparado de diferentes métodos de secagem da polpa de abacate da variedade Breda sobre parâmetros de qualidade do óleo bruto obtido.

\section{MATERIAIS E MÉTODOS}

Abacates da variedade Breda, doados por um produtor de São Sebastião do Paraíso/MG, foram envoltos em papel e acondicionados em caixa de papelão até alcançar o ponto ideal de maturação, observado pela firmeza da polpa e medida do teor de sólidos solúveis (cerca de $8^{\circ}$ Brix); sanitizados em água clorada a $100 \mathrm{mg} . \mathrm{L}^{-1}$ por $15 \mathrm{~min}$, posteriormente cortados, sendo a polpa separada e tratada com solução de ácido cítrico a $1 \%$ por $15 \mathrm{~min}$. A massa total de polpa resultante foi fracionada em três porções iguais, sendo que cada uma foi submetida a um processo de secagem, a $40{ }^{\circ} \mathrm{C}$, a $60{ }^{\circ} \mathrm{C}$ ou liofilização. Os processos de secagem a $40{ }^{\circ} \mathrm{C}$ ou a $60^{\circ} \mathrm{C}$ ocorreram em estufa com circulação de ar (modelo MA035, Marconi), sendo a polpa triturada e disposta sobre folhas de alumínio. Quando as amostras atingiram o teor de umidade de aproximadamente de 5-6\%, foram armazenadas em frascos de vidro revestidos com folhas de alumínio e estocados em freezer $\left(-18{ }^{\circ} \mathrm{C}\right)$ até a extração do óleo. $\mathrm{O}$ processo de liofilização ocorreu em liofilizador (modelo L101, LIOBRAS) a $387 \mu \mathrm{mHg}$ de pressão e $47{ }^{\circ} \mathrm{C}$ de temperatura até obter um produto com umidade final de aproximadamente 5-6\%. Antes da liofilização, a polpa foi congelada em ultra-freezer $\left(-80{ }^{\circ} \mathrm{C}\right.$ por $\left.24 \mathrm{~h}\right)$. A amostra liofilizada foi acondicionada da mesma forma que as anteriores até o momento da extração do óleo.

Uma vez desidratadas, as amostras tiveram o óleo extraído por éter de petróleo em Soxhlet. Para extração foram pesadas, aproximadamente, $30 \mathrm{~g}$ de amostra, acondicionadas em cartucho de papel filtro, previamente desengordurado, sendo utilizado éter de petróleo como solvente extrator. $\mathrm{O}$ processo foi conduzido por um período de $5 \mathrm{~h}$ e após, a micela obtida foi dessolvatada em rotaevaporador (modelo Q-344B2, QUIMIS). O óleo obtido foi acondicionado em frascos de vidro fechados hermeticamente e estocado em freezer $\left(-18{ }^{\circ} \mathrm{C}\right)$ até o momento das análises. As amostras foram submetidas, em triplicata, às determinações do índice de acidez (I.A.), índice de iodo (I.I.), índice de refração (I.R.) e índice de peróxidos (I.P.), seguindo-se metodologia descrita por American Oil Chemists' Society (1992). Os resultados foram submetidos à análise de variância (ANOVA) e 

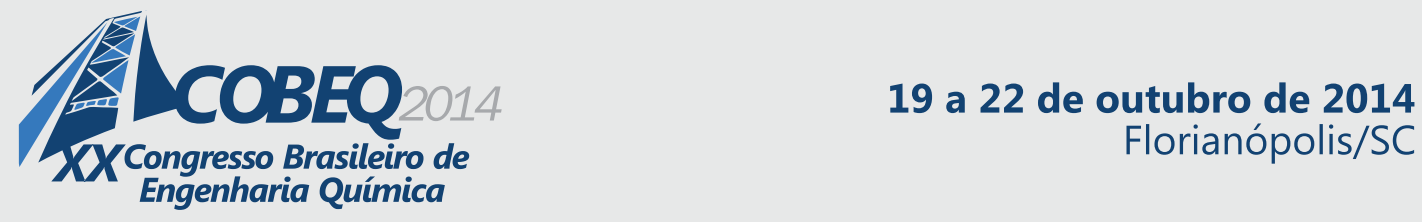

teste de Tukey ao nível de significância de 5\%, para comparação das médias.

\section{RESULTADOS E DISCUSSÕES}

Os resultados demonstraram que os parâmetros de qualidade avaliados, em geral, variam segundo o processo de secagem aplicado à polpa. De um modo geral, quanto maior a temperatura do processo de secagem, maiores modificações foram observadas. Os índices de acidez, iodo, peróxidos e refração são importantes parâmetros utilizados na classificação e caracterização de óleos vegetais. Do ponto de vista da qualidade, eles indicam possíveis alterações ao nível dos triglicerídeos (principais constituintes do óleo), destacando-se reações hidrolíticas e oxidativas (Instituto Adolfo Lutz, 1985), que, por sua vez, são passíveis de ocorrer ao longo de toda a cadeia de produção de óleos e gorduras. A temperatura do processo influencia no controle dessas reações, uma vez que ela é um dos principais aceleradores da degradação e oxidação de lipídeos (Rodrigues et al., 2012; Boselli et al., 2009). Quanto menor a exposição de fontes oleaginosas ao calor, ao longo do processo, menor a ocorrência dessas alterações. Isso justifica a razão pela qual o óleo obtido da polpa liofilizada apresentou, estatisticamente, menores alterações nesses parâmetros, comparado aquele obtido da polpa de abacate seca a $40{ }^{\circ} \mathrm{C}$ ou a $60^{\circ} \mathrm{C}$.

Tabela 1 - Parâmetros de qualidade do óleo extraído da polpa de abacate submetida a diferentes métodos de secagem

\begin{tabular}{ccccc}
\hline \multirow{2}{*}{ Processo de Secagem } & \multicolumn{4}{c}{ Parâmetros de qualidade } \\
\cline { 2 - 5 } & I.I. & I.P. & I.R. & I.A. \\
\hline Liofilização & $80,86 \mathrm{c}$ & $2,6 \mathrm{a}$ & $1,461 \mathrm{a}$ & $1,61 \mathrm{a}$ \\
Secagem a $40^{\circ} \mathrm{C}$ & $79,82 \mathrm{~b}$ & $3,0 \mathrm{~b}$ & $1,461 \mathrm{a}$ & $1,65 \mathrm{~b}$ \\
Secagem a $60^{\circ} \mathrm{C}$ & $78,25 \mathrm{a}$ & $3,5 \mathrm{c}$ & $1,457 \mathrm{a}$ & $1,63 \mathrm{c}$ \\
\hline
\end{tabular}

Dados: I.I. = índice de iodo, em g de $\mathrm{I}_{2} / 100 \mathrm{~g}$ de óleo; I.P. = índice de peróxidos, em $\mathrm{mEq} / 1000 \mathrm{~g}$ de óleo; I.R.= índice de refração, valor adimensional; I.A.= índice de acidez, em g de ácido oleico $/ 100 \mathrm{~g}$ de óleo. Valores seguidos de letras diferentes, na mesma coluna, diferem estatisticamente a $5 \%$ pelo teste de Tukey.

Dos parâmetros avaliados em cada tratamento, o I.I. e o I.P., os quais se relacionam ao grau de oxidação de lipídios (Guillén; Uriarte, 2012; Santas et al., 2014), parecem ter maior susceptibilidade à alteração, conforme se eleva a temperatura do processo de secagem. A oxidação de lipídios ocorre ao nível das ligações duplas de ácidos graxos insaturados na presença de fatores pró-oxidantes, tais como metais, ácidos graxos livres, oxigênio, pigmentos, luz e calor. Caracteriza-se por uma reação em cadeia, composta por três fases distintas, iniciação, propagação e terminação (Pingret et al., 2013), com formação contínua de compostos primários, em particular os hidroperóxidos (Santas et al., 2014), normalmente denominados peróxidos (Oetterer et al., 2006).

Uma vez que o I.P. determina peróxidos presentes numa amostra, ele tem relação positiva com o grau de oxidação de lipídios (Pingret et al., 2013). O I.I., por sua vez, é uma medida de insaturação química de lipídeos. A perda dessas insaturações pelo processo de oxidação implica na diminuição desse valor (Guillén; Uriarte, 2012). Avaliando-se os processos de secagem empregados, conforme 


\section{9 a 22 de outubro de 2014 \\ Florianópolis/SC}

houve elevação da temperatura, foram observados aumento do I.P. e diminuição do I.I. no óleo de abacate. Isso demonstra o efeito da temperatura do processamento como um dos os principais fatores de risco para o processo de oxidação de lipídios (Rodrigues et al., 2012; Boselli et al., 2009).

Em relação ao I.A., o óleo extraído da polpa liofilizada apresentou valor significativamente menor que os demais. Comparando-se os óleos extraídos da polpa por secagem a $40{ }^{\circ} \mathrm{C}$ e a $60{ }^{\circ} \mathrm{C}$, o que apresentou maior I.A. foi o obtido da polpa a $40{ }^{\circ} \mathrm{C}$. A temperatura de processamento pode interferir na acidez de óleos vegetais de duas maneiras: sendo fonte de calor à catálise da hidrólise química de triacilgliceróis (Rodrigues et al., 2012; Boselli et al., 2009) ou dando condições ideais à atuação de lipases endógenas (Mraicha et al., 2010;), ou produzidas por micro-organismos contaminantes (Ciafardini et al., 2006). Estudos realizados com azeite de oliva demonstraram que a atividade dessas enzimas neste azeite é intensa na faixa de temperatura entre 20 e $30{ }^{\circ} \mathrm{C}$, sendo totalmente inibida em temperaturas acima de $60{ }^{\circ} \mathrm{C}$ (Ciafardini et al., 2006). Com base nisso, é provável que a secagem a $40{ }^{\circ} \mathrm{C}$ tenha conferido condições à ação de lípases presentes na polpa, resultando um óleo com acidez maior que o extraído da polpa seca a $60{ }^{\circ} \mathrm{C}$, onde estas enzimas devem ter sido totalmente inativadas.

Diferentemente dos demais parâmetros, não foi observada diferença estatística no I.R. entre as amostras, indicando que o processo de secagem da polpa não interferiu nesse parâmetro. O I.R. é característico de cada tipo de óleo, estando relacionado, com o número de insaturações no óleo, além do grau de oxidação, teor de ácidos graxos livres e tratamento térmico do óleo (Instituto Adolfo Lutz, 1985). Esse valor mostra que as alterações ocasionadas pelo processo de secagem, anteriormente destacados, não foram suficientes para modificar o comportamento óptico das amostras.

Os resultados encontrados neste trabalho foram comparados com os apresentados por óleos de abacate de diferentes cultivares, obtidos por diferentes processos de extração (Tabela 2).

Tabela 2 - Relatos sobre Índices de iodo (I.I.), de peróxidos (I.P.), de refração (I.R.) e de acidez (I.A.) de óleo bruto de abacate de diferentes variedades, extraído por diferentes processos tecnológicos

\begin{tabular}{cccccc}
\hline \multirow{2}{*}{ Referência } & \multirow{2}{*}{ Cultivar } & \multicolumn{4}{c}{ Parâmetros de qualidade } \\
\cline { 3 - 6 } & & I.I. & I.P. & I.R. & I.A. \\
\hline Bora et al. $(2001)^{1}$ & Fuerte & 77,6 & 1,40 & 1,4608 & 1,23 \\
Ortega et al. $(2013)^{2}$ & Hass & 85,65 & 3,79 &.. & 1,29 \\
Santana et al. $(2011)^{3}$ & Hass &.. &.. &.. & $0,42-0,70$ \\
Salgado et al. $(2008)^{4}$ & Margarida & 96,31 & 20,58 & .. & .. \\
\hline
\end{tabular}

Dados: I.I. = índice de iodo, em $\mathrm{g}$ de $\mathrm{I}_{2} / 100 \mathrm{~g}$ de óleo; I.P. = índice de peróxidos, em $\mathrm{mEq} / 1000 \mathrm{~g}$ de óleo; I.R.= índice de refração, valor adimensional; I.A.= índice de acidez, em g de ácido oleico/100g de óleo; ${ }^{1,2,3,4}=$ métodos de extração do óleo de abacate: ${ }^{1}$ extração com hexano, sendo a polpa previamente seca a $50^{\circ} \mathrm{C} / 24 \mathrm{~h} ;{ }^{2}$ extração em soxhlet a $69 \pm 1^{\circ} \mathrm{C} / 4 \mathrm{~h}$ com hexano, sendo que a polpa não recebeu nenhum processo de secagem; ${ }^{3}$ extração com éter de petróleo a $45^{\circ} \mathrm{C} / 1 \mathrm{~h}$ e extração por prensagem à frio, sendo a polpa previamente seca a $60^{\circ} \mathrm{C}$ até peso constante; ${ }^{4}$ extração em soxhlet com hexano e acetona na proporção 1:1 ou extração em soxhlet em hexano, sendo a amostra previamente seca a $50^{\circ} \mathrm{C}$ até peso constante. 


\section{9 a 22 de outubro de 2014 \\ Florianópolis/SC}

O óleo da cultivar Breda, independente do processo de secagem da polpa, apresentou I.I. próximo ao valor encontrado por Bora et al. (2001), enquanto que os valores encontrados por Ortega et al. (2013) e Salgado et al. (2008) indicaram que o óleo estava em melhor qualidade. Quanto ao I.P., verificou-se que os óleos da cultivar Breda apresentaram condição superior as relatadas por Ortega et al. (2013) e Salgado et al. (2008). Já em relação ao I.A., observou-se que foi mais elevado que os valores reportados por Bora et al. (2001), Ortega et al. (2013) e Santana et al. (2011). Esses resultados reforçam a grande variabilidade dos parâmetros de qualidade de óleos de abacate, conforme se varia a cultivar e o processo pelo qual se obteve o óleo.

Do ponto de vista da manutenção da qualidade do óleo, o processo de secagem da polpa de abacate por liofilização apresentou-se vantajoso, corroborando com os resultados encontrados por Santos et al., 2014. Porém, todos os tratamentos produziram óleos com características similares, e em certos casos até superiores as descritas na literatura (Bora et al., 2001; Ortega et al., 2013). Assim, para a decisão de qual o melhor processo é necessário estudos mais detalhados, inclusive associados a aspectos econômicos do processo. Vale frisar que são limitados os estudos sobre a influência de operações de processamento sobre a qualidade do óleo de abacate, além de não haver, na legislação brasileira, alegação sobre identidade e qualidade desse óleo.

\section{CONCLUSÕES}

Os resultados demonstraram que os parâmetros de qualidade avaliados, em geral, variam segundo o processo de secagem aplicado à polpa. De um modo geral, quanto maior a temperatura do processo de secagem, maiores modificações são produzidas no óleo. O óleo obtido da polpa liofilizada apresentou, estatisticamente, menores alterações nos parâmetros estudados, comparado aquele obtido da polpa de abacate seca a $40{ }^{\circ} \mathrm{C}$ ou a $60{ }^{\circ} \mathrm{C}$. Os índices de peróxidos e acidez foram os parâmetros que mostram maiores variações. Em relação ao índice de peróxidos, observou-se efeito negativo do aumento da temperatura de secagem, entretanto, no índice de acidez (maior para o óleo da polpa seca a $40{ }^{\circ} \mathrm{C}$ ), observou-se efeito deletério do tempo de secagem, que foi maior no processo de estufa a $40{ }^{\circ} \mathrm{C}$, e pode ter possibilitado a ação de lípases. Diferentemente dos demais parâmetros, não foi observada diferença estatística no índice de refração entre as amostras, indicando que o processo de secagem da polpa não interferiu nesse parâmetro. Esses resultados vêm contribuir com informações para estudos de otimização do processamento do abacate visando a extração do óleo.

\section{REFERÊNCIAS}

AMERICAN OIL CHEMISTS' SOCIETY. Official and tentative methods of the American Oils Chemists’ Society. Champaign: American Oils Chemists' Society, 1992.

BORA, S. P.; NARAIN, N.; ROCHA, R. V. M.; PAULO, M. Q. Characterization of the oils from the pulp and seeds of avocado (cultivar: Fuerte) fruits. Grasas y Aceites, v. 52., n. 3-4, p.171-174, 2001. Disponível em: <http://grasasyaceites.revistas.csic.es/index.php/grasasyaceites/article/view/353>. Acesso em 04 de abr. de 2014.

BOSELlI, E.; DI LECCEA, G.; STRABBIOLI, R.; PIERALISI, G.; FREGAA, N. G. Are virgin 
olive oils obtained below $27 \mathrm{C}$ better than those produced at higher temperatures? LWT - Food Sc. Technol., v. 42, n. 3, p. 748-757, 2009.

CAMPOS, R. A. Otimização de método de extração de óleo presente em polpa de abacate. 2009. $68 \mathrm{f}$. Dissertação (Mestrado em Química) - Instituto de Química, Universidade Estadual Paulista, Araraquara, 2009.

CIAFARDINI, G.; ZULLO, B.A.; CIOCCIA, G.; IRIDE, A. Lipolytic activity of Williopsis californica and Saccharomyces cerevisiae in extra virgin olive oil. Int. J. Food Microbiol., v. 107, n. 1, p. 27-32, 2006.

FENNEMA, O. R. Química de los alimentos. 2 ed. Zaragoza: Acribia, 1993.

GUILLÉN, M. D.; URIARTE, P. S. Simultaneous control of the evolution of the percentage in weight of polar compounds, iodine value, acyl groups proportions and aldehydes concentrations in sunflower oil submitted to frying temperature in an industrial fryer. Food Control, v. 24, n. 1-2, p. 50-56, 2012.

INSTITUTO ADOLFO LUTZ. Normas Analíticas do Instituto Adolfo Lutz. São Paulo: Instituto Adolfo Lutz, 1985. v. 1.

JACOBO-VELÁZQUEZ, A. D. HERNÁNDEZ-BRENES, C. Stability of avocado paste carotenoids as affected by high hydrostatic pressure processing and storage. Innovative Food Sci. Emerg. Technol., v. 16, p. 121-128, 2012.

MRAICHAA, F.; KSANTINI, M.; ZOUCHB, O.; AYADI, M.; SAYADI, S.; BOUAZIZ, M. Effect of olive fruit fly infestation on the quality of olive oil from Chemlali cultivar during ripening. Food Chem. Toxicol., v. 48, n. 11, p. 3235-3241, 2010.

OETTERER, M., REgitANO-D'ARCE, M. A. B., SPOTO, M. H. F. Fundamentos de Ciência e Tecnologia de Alimentos. Barueri: Manole, 2006.

ORTEGA, J. A. A.; LÓPEZ, M. R.; TORRE, R. R. R. Effect of electric Field treatment on avocado oil. Int. J. Res. Agric. Food Sc., v. 1, n. 1, 2013. Disponível em: < http://www.ijsk.org/uploads/3/1/1/7/3117743/2_avocado_oil.pdf>. Acesso em 04 de abr. de 2014.

PINGRET, D., FABIANO-TIXIER, A., CHEMAT, F. Degradation during application of ultrasound in food processing: a review. Food Control, v. 31, n. 2, p. 593-606, 2013.

RODRIGUES, N.; MALHEIROA, R., CASAL, S.; ASENSIO-S.-MANZANERAC, M. C.; BENTOA, A.; PEREIRA, J. A. Influence of spike lavender (Lavandula latifolia Med.) essential oil in the quality, stability and composition of soybean oil during microwave heating. Food Chem. Toxicol., v. 50, n. 8, p. 2894-2901, 2012.

SALGADO, J. M.; DANIELI, F.; REGITANO-D'ARCE, M. A. B.; FRIAS, A.; MANSI, D. N. O óleo de abacate (Persea americana Mill) como matéria-prima para a indústria alimentícia. Ciênc. 


\section{Florianópolis/SC}

Tecnol. Aliment., v. 28, p. 20-26, 2008.

SANTANA, I.; CABRAL, L. M. C. ; FREITAS, S.P.; TORRES, A. G. Efeito do pré-tratamento na extração do óleo da polpa de abacate hass (Persea americana). In: Congresso Brasileiro de Processamento de Frutas e Hortaliças, 2., 2011, Rio de Janeiro. Anais...Rio de Janeiro: Embrapa Agroindústria de Alimentos, 2011. Disponível em: < http://www.alice.cnptia.embrapa.br/handle/doc/916683>. Acesso em 04 de jul. de 2013.

SANTAS, J., GUZMÁN, Y. J., GUARDIOLA, F., RAFECAS, M., BOU, R.. High-throughput analysis of lipid hydroperoxides in edible oils and fats using the fluorescent reagent diphenyl-1 pyrenylphosphine. Food Chem., no prelo, 2014. 